\title{
Irrigation technology adoption and its implication for water conservation in the Texas High Plains: a real options approach
}

\author{
Sangtaek Seo ${ }^{\mathrm{a}, *}$, Eduardo Segarra ${ }^{\mathrm{b}}$, Paul D. Mitchell ${ }^{\mathrm{c}}$, David J. Leatham ${ }^{\mathrm{d}}$ \\ ${ }^{a}$ Chungbuk National University, Cheongju, Chungbuk, 361-763, South Korea \\ ${ }^{\mathrm{b}}$ Texas Tech University, Box 42132, Lubbock, TX 79409, USA \\ ${ }^{c}$ University of Wisconsin-Madison, 411 Taylor Hall, Madison, WI 53706, USA \\ ${ }^{\mathrm{d}}$ Texas A\&M University, 2124 TAMU, College Station, TX 77843, USA
}

Received 24 May 2006; received in revised form 19 December 2006; accepted 10 July 2007

\begin{abstract}
Water shortage has been a significant issue for several decades in the Texas High Plains. Agriculture has been identified as the main activity contributing to this shortage. To address this issue, many efforts have been focused on the possible adoption of sophisticated irrigation systems with high levels of water application efficiency. In this study, the entry and exit thresholds for the low-energy precision application (LEPA) system are analyzed simultaneously in cotton farming in the Texas High Plains using a real options approach. The results show that the LEPA system is profitable only when cotton price is set above $\$ 1.59 / \mathrm{kg}$. The exit (entry) threshold is consistently low (high) over a range of values for parameter changes including investment cost, exit cost, variable cost, risk-adjusted discount rate, and volatility rate, so it is unlikely that farmers with irrigation systems in place would leave them easily. This implies that to attain the goal of saving water, Lubbock County needs to focus on convincing current farmers to replace old irrigation systems with new ones.
\end{abstract}

JEL classification: Q14, Q16, Q25

Keywords: Irrigation systems; Real options; Texas High Plains; Cotton farming; Water conservation

\section{Introduction}

Water scarcity is a growing concern for sustainable agriculture worldwide. About a third of the population in developing countries is likely to experience severe water scarcity by the year 2025 (Molden et al., 2001). Many nations have attempted to reform their water management systems by improving their irrigation systems (Johnson et al., 1995; Meinzen-Dick et al., 2002). In addition, to alleviate the issue of water scarcity, many efforts have been devoted to the development of groundwater resources. Thus, the use of groundwater irrigation in many parts of the world has become the mainstay of agriculture (Shah, 2005).

In the United States, irrigated agriculture heavily depends on groundwater supplies, where two thirds of all irrigated areas use groundwater supplies. About 1.8 million ha out of 6.4 million ha, where groundwater aquifers are declining, are located in Texas (National Research Council, 1996). The Texas High

\footnotetext{
${ }^{*}$ Corresponding author. Tel.: +82-43-261-2590; fax +82-43-271-5920. E-mail address: stseo@chungbuk.ac.kr (S.Seo).
}

Plains is the primary location in Texas that uses groundwater from aquifers at levels that are not sustainable. In this region, the Ogallala aquifer is the only and significantly decreasing source of groundwater (Arabiyat et al., 1999). The level of the Ogallala aquifer is being continuously reduced because the depletion rate exceeds the recharge rate. The resulting water shortage has been a serious issue for a long time in the Texas High Plains.

The agricultural sector is blamed for aquifer depletion in the Texas High Plains. Among the crops produced in this region, cotton is the major crop and uses a significant amount of water. Irrigated cotton areas constitute $54 \%$ of all cotton areas and are continuously increasing, and so water use is also increasing. This is a relatively high proportion of irrigated cotton production compared with the state average of only $40 \%$ of all cotton areas being irrigated in 2003 (USDA-NASS, 2005).

Different irrigation systems have been developed in agriculture to attempt to balance water use and recharge rates. Traditionally, furrow irrigation and low-pressure sprinkler systems have been the most commonly used irrigation systems in the Texas High Plains. However, with increasing concerns about water shortages, new irrigation systems with high water 
application efficiency are being developed and studied. In recent years, the low-energy precision application (LEPA) system has received significant attention and is being widely adopted. However, subsurface drip irrigation (SDI) system is now being considered in the region because of its high water application efficiency. In addition, variable rate irrigation (VRI) system alternatives are currently being tested by a private company and Texas Cooperative Extension in the region. The VRI system has been demonstrated in a representative farm and found to be technically feasible (Almas et al., 2003).

Recently, Seo et al. (2006) showed that among the above alternatives only LEPA is economically feasible in the Texas High Plains, even though SDI and VRI have higher water application efficiency. This result is consistent with the economic analysis of LEPA and SDI conducted by Amosson et al. (2001), which shows that the SDI is not economically feasible compared with LEPA because of its high investment cost and small gains in water application efficiency. These results may have an important implication for water savings in the region: the positive profitability of LEPA could result in an increase in groundwater use due to expansion of irrigated area. That is, the effort to develop or introduce new irrigation systems with higher water application efficiency may counteract the desire to save groundwater (Segarra and Feng, 1994; Seo et al., 2006).

These studies do not definitively support this conclusion because they considered the economic feasibility from the investment decision perspective only. Even though a farmer installs an irrigation system, he/she may later disinvest in the irrigation system depending on future economic conditions or uncertainty. If the future economic conditions are unfavorable to irrigation farmers, farmers will be willing to leave irrigated farming, thus increasing ground water savings. However, highly uncertain future economic conditions might delay the farmers' decision to dismiss irrigation systems until the uncertainty is resolved. In addition, if farmers have the option to disinvest (disinvestment flexibility), it encourages them to invest in irrigation systems because they get an additional put option value from the investment that can be exercised in the future, thus affecting trigger values to invest (Abel et al., 1996). Thus, more analysis of disinvestment decisions is required to depict economic feasibility more accurately for farmers and clarify the implications for water saving.

This issue can be resolved to some degree by analyzing the entry and exit trigger values using the real options approach. This approach provides the conceptual framework and empirical methodology commonly used to examine irreversible and uncertain investments in real assets (Dixit and Pindyck, 1994, p. 7). In real options, the investor is assumed to have an option to invest or/and disinvest, called investment or/and disinvestment flexibility. By incorporating this option value, the real options approach provides a better measure of the value of an investment compared with the more traditional net present value (NPV) approach (Trigeorgis, 1996, p. 15). When the disinvestment (exit) decision is included in the investment analysis, the trigger values to entry and exit in irrigation systems must be si- multaneously determined, which typically requires a numerical solution (Dixit and Pindyck, 1994, p. 218).

The purpose of this study is to analyze trigger values for the decision to invest and disinvest simultaneously, and to derive their implications for water conservation in irrigated cotton in the Texas High Plains. Because LEPA has been demonstrated to be the most economically feasible in the Texas High Plains (Amosson et al., 2001; Seo et al., 2006), this analysis examines only LEPA. This focus puts attention more directly on the effect of incorporating simultaneous investment and disinvestment decisions into the analysis, the topic of this article, rather than on comparing technologies that have already been compared. This study can help farmers examine investment and disinvestment decisions by identifying the entry and exit thresholds for LEPA. In addition, the justification of the regional effort to save ground water may be evaluated to some degree by identifying the economic feasibility and disinvestment possibility. In what follows, we first develop a conceptual framework of farmers' decision making for investment and disinvestment in irrigation systems using a real options approach. Next we describe the data and our results.

\section{Conceptual framework}

\subsection{Profit and random yield process}

Define profit $\left(\pi_{i}\right)$ for an irrigated cropping system $(i=1$ for irrigated farming and $i=0$ for nonirrigated farming) as the difference between revenue $R_{i}$ and total cost $C_{i}$ :

$\pi_{i}=R_{i}-C_{i}$,

where revenue is the product of market price, $p$, and yield, $y_{i}$, $\left(R_{i}=p y_{i}\right)$, and total cost is the product of the price of groundwater, $w_{i}$, and the amount of groundwater used, $x_{i}$, plus all the other variable and fixed costs, $O C_{i},\left(C_{i}=w_{i} x_{i}+O C_{i}\right)$. In this study, we only consider cash flows in profit, revenue, and total cost for the purpose of investment analysis. We normalize profit by the output price because the output price that farmers realize is relatively stable compared with yield because of government intervention, such as the marketing loan rate, counter cyclical payments, or direct payments. For example, the volatility rate $\sigma$ is 0.101 for the annual market price from 1984 to 2003 when the marketing loan rate creates a price floor at $\$ 0.52 / \mathrm{lb}$ (volatility is 0.174 without the program). The comparable volatility rate for yield is 0.267 , indicating that yield variability is the primary source of uncertainty. Hence, we ignore price variability and vary the output price in the analysis to evaluate the effect of the change in output price. Stochastic per hectare-irrigated yield $y_{1}$ $(\mathrm{kg} / \mathrm{ha})$ is a function of water use $x_{1}$ (hectare-meters per hectare) for the irrigation system and a stochastic factor $\theta$ with expected value of 1 due to effects such as weather and infestations of insects, weeds, and plant pathogens, given all other inputs. We assume a general production function $y_{1}=\theta f\left(x_{1} \mid \mathbf{x}\right)$ to derive the optimal level of water use, where $\mathbf{x}$ is the vector that includes 
all other inputs except water use (Dixit and Pindyck, 1994, p. 297).

The profit maximization first-order condition $f^{\prime}\left(x_{1} \mid \mathbf{x}\right)=w_{1}$ defines the optimal level of water use $x_{1}^{*}$ (the level at which marginal revenue from water use equals its marginal cost), which then defines the optimal yield level $y_{1}^{*}=\theta f\left(x_{1}^{*} \mid \mathbf{x}\right)$. Nonirrigated yield $y_{0}$ is also random, depending on the same factors as irrigated yield (e.g., inputs, insect, weed, disease pressure, hail, and wind damage), except that it receives no irrigation water. To capture this connection, yield without irrigation is proportional to yield with irrigation, a relationship supported by the historical county yields in the region (USDA-NASS, 2005). ${ }^{1}$ Hence, we use $y_{0}=b y_{1}$, where $b<1$.

No water market exists to govern the use of groundwater in the Texas High Plains. Thus, the input price $w_{1}$ represents the cost to pump and apply a hectare-meter of water, where this cost is for energy and delivery costs, plus equipment maintenance and labor expenses. Cost will differ between the two systems. Nonirrigated cotton will have no cost for irrigation $\left(w_{0} x_{0}=0\right)$ and the total costs will likely be lower than for irrigated cotton, as a result of such factors as using less fertilizer and having lower harvest costs due to lower yields. Hence, $C_{0}=O C_{0}<$ $C_{1}$. For this analysis, given the proportional yield assumption $\left(y_{0}=b y_{1}\right)$, the effect of this cost difference will depend on $\Delta C=$ $C_{1}-C_{0}$.

Given the optimal water use $x_{1}^{*}$, the yield flow $y_{1}^{*}$ is assumed to follow a geometric Brownian motion process (Carey and Zilberman, 2002; Isik et al., 2003; Price and Wetzstein, 1999; Purvis et al., 1995). Dropping the superscript * and the subscript $i=1$ for smooth development of the model, the geometric Brownian motion process is defined as

$d y=\alpha y d t+\sigma y d z$,

where $\alpha$ is the drift (trend) rate, $\sigma$ is the volatility rate, $d t$ is the small time increment, and $d z$ is the continuous-time stochastic Wiener process defined as $d z=\varepsilon_{t} \sqrt{d t}$, where $\varepsilon_{\mathrm{t}} \sim \mathrm{N}(0,1)$. The expected value of the Wiener process is $\mathrm{E}[d z]=0$ and its variance is $\mathrm{E}\left[(d z)^{2}\right]=d t$, where $\mathrm{E}[\cdot]$ is the expectation operator (see Dixit and Pindyck [1994] for more detail).

\subsection{Investment and disinvestment decisions}

The value function of nonirrigated farming $V_{0}$ is defined as the NPV of the future profit flow with an appropriate discounting factor. The farmer who wishes to invest in an irrigation system has to choose an investment timing $t^{*}$ that maximizes

\footnotetext{
${ }^{1}$ We note that there is no direct casual relationship between nonirrigated yield and irrigated yield in a theoretical sense. But both variables are affected by some of the same factors mentioned in the paper and move together with the same direction. Thus we approximate this relationship using econometric model as shown in the actual data. We are grateful to a reviewer for raising this point. We also note that the focus of this paper is on the real options approach, not on estimating a structural econometric model.
}

the NPV of profit subject to the stochastic movement of random yield over time:

$V_{0}(y)=\max \mathrm{E}\left[\int_{0}^{\infty} \pi_{0} e^{-\rho t} d t\right]$,

subject to Eqs. (1) and (2), where $\rho$ is the risk-adjusted discount rate equal to the risk-free discount rate $r$ plus the risk premium $\Phi$.

Because the yield $y$ evolves stochastically, Eq. (3) cannot be solved analytically to produce an investment timing point $t^{*}$. Instead, a critical value $y_{h}$ that triggers investment in the irrigation system will be determined following the investment rule that it is optimal to invest only when $y \geq y_{h}$ (Dixit and Pindyck, 1994). Nonirrigated farming produces no benefit from the irrigation system until the investment is undertaken. The only return from the irrigation system is the capital appreciation from holding the option to invest that is affected by the stochastic movement of random yield. Thus, the stochastic dynamic optimization (Eq. (3)) can be expressed as the following Bellman equation (Pindyck, 1991):

$\rho V_{0}(y) d t=\pi_{0}+E\left[d V_{0}(y)\right]$.

Expanding the right-hand side of Eq. (4) using Ito's Lemma gives the following differential equation (Pindyck, 1991):

$\frac{1}{2} \sigma^{2} y^{2} V_{0}^{\prime \prime}(y)+\alpha y V_{0}^{\prime}(y)-\rho V_{0}(y)+\pi_{0}=0$,

where $V_{0}^{\prime}$ and $V_{0}^{\prime \prime}$ are the first and second derivative with respect to $y$. Similarly, the differential equation for irrigated farming $V_{1}$ is

$\frac{1}{2} \sigma^{2} y^{2} V_{1}^{\prime \prime}(y)+\alpha y V_{1}^{\prime}(y)-\rho V_{1}(y)+\pi_{1}=0$.

Both differential equations include linear homogeneous parts so that the general solutions contain a linear combination of any two independent solutions. The solution form of this homogeneous part is $V(y)=A y^{\beta}$, where $A$ is the constant to be determined as a part of the solution, if $\beta$ satisfies the fundamental quadratic equation:

$\rho-(\rho-\delta) \beta-\frac{1}{2} \sigma^{2} \beta(\beta-1)=0$,

where $\delta$ is the risk- and growth (trend)-adjusted discount rate, $\delta=\rho-\alpha$ (Dixit and Pindyck, 1994). The respective positive and negative roots of this quadratic equation are

$$
\begin{aligned}
& \beta_{1}=\frac{1}{2}-\frac{(\rho-\delta)}{\sigma^{2}}+\sqrt{\left[\frac{(\rho-\delta)}{\sigma^{2}}-\frac{1}{2}\right]^{2}+\frac{2 \rho}{\sigma^{2}}}>1, \quad \text { and (8) } \\
& \beta_{2}=\frac{1}{2}-\frac{(\rho-\delta)}{\sigma^{2}}-\sqrt{\left[\frac{(\rho-\delta)}{\sigma^{2}}-\frac{1}{2}\right]^{2}+\frac{2 \rho}{\sigma^{2}}}<0
\end{aligned}
$$


Equation (5) also includes a nonhomogeneous part that has the solution $\pi_{0} / \rho$. The general solution of the differential equations can be written as

$V_{0}(y)=A_{0} y^{\beta_{1}}+B_{0} y^{\beta_{2}}+\frac{\pi_{0}}{\rho}$,

$V_{1}(y)=A_{1} y^{\beta_{1}}+B_{1} y^{\beta_{2}}+\frac{\pi_{1}}{\rho}$

where $\beta_{1}$ and $\beta_{2}$ are the respective positive and negative roots of the fundamental quadratic (Eq. (7)) and $A_{0}, B_{0}, A_{1}$, and $B_{1}$ are constants to be determined as part of the respective solutions for the value function of nonirrigated farming and irrigated farming. The first two terms in Eqs. (10) and (11), respectively, denote the value of the option to invest for the nonirrigating farmer and the value of the option to exit for the farmer with irrigation. The last term in each equation denotes the value of the profit flow from farming. At very low yield levels, the probability of investing in an irrigation system is small, thus the value of the option to invest in $(10)$ approaches zero $\left(B_{0}=0\right)$. On the other hand, at very high yield levels, the probability of exiting irrigated farming is also very small, thus the value of the option to exit approaches zero $\left(A_{1}=0\right)$. Thus, the value functions of nonirrigated farming and irrigated farming simplify to

$V_{0}(y)=A_{0} y^{\beta_{1}}+\frac{\pi_{0}}{\rho}, \quad$ and

$V_{1}(y)=B_{1} y^{\beta_{2}}+\frac{\pi_{1}}{\rho}$.

The nonirrigated farmer is willing to pay a lump-sum investment cost $I$ at the investment threshold $y_{h}$ that triggers investment in the irrigation system as long as the investment is expected to be profitable. By exercising the investment option at a cost $I$, the farmer gets a business with an irrigation system and a disinvestment option in irrigation systems, and loses the value of the option to invest. This relationship can be described by the respective value-matching condition and the smooth-pasting condition:

$V_{0}\left(y_{h}\right)=V_{1}\left(y_{h}\right)-I, \quad$ and

$V_{0}^{\prime}\left(y_{h}\right)=V_{1}^{\prime}\left(y_{h}\right)$

The value-matching condition (14) requires the value of nonirrigated farming to equal the value of irrigated farming at the entry threshold $y_{h}$ when the investment cost $I$ is paid. The smooth-pasting condition (15) requires the same slopes of the value of the nonirrigated farming and the value of the irrigated farming at the entry threshold level (Merton, 1973).

Similarly, the irrigated farmer is willing to discontinue the irrigation system when irrigated farming is not profitable. To discontinue the irrigation system, the irrigated farmer must pay a lump-sum cost $D$ because the disinvestment decision entails a clearing cost of the irrigation system and a restoring cost of the farmland for other farming practices. On the other hand, the irrigation system can be partially reversible, thus facilitating the disinvestment decision from irrigated farming. This reversibility may affect the investment decision (Abel et al., 1996). However, the value of the irrigation system lost when disinvesting is insignificant compared with the initial investment cost because when irrigated farming becomes unprofitable, the same conditions will apply to other farms in the region, thus depressing the salvage value of irrigation equipment. As a result, we do not consider reversibility in this study.

By exercising the value of the option to exit at a cost $D$, the farmer leaves irrigated farming, but has the option to invest in an irrigation system again. This relationship can be described by adding value-matching and smooth-pasting conditions comparable to Eqs. (14) and (15):

$V_{1}\left(y_{l}\right)=V_{0}\left(y_{l}\right)-D$,

$V_{1}^{\prime}\left(y_{l}\right)=V_{0}^{\prime}\left(y_{l}\right)$

where $y_{l}$ is the exit threshold that triggers disinvestment in an irrigation system. The value-matching condition (16) requires the value of irrigated farming to equal the value of nonirrigated farming at the exit threshold $y_{l}$ when the disinvestment $\operatorname{cost} D$ is paid. The smooth-pasting condition (17) requires the same slopes of the value of irrigated farming and the value of nonirrigated farming at the exit threshold level.

Substituting the two value functions in Eqs. (12) and (13) into Eqs. (14)-(17) and using $R_{1}=y_{1}$, we have the following system of simultaneous equations:

$$
\begin{aligned}
& -A_{0} y_{h}^{\beta_{1}}+B_{1} y_{h}^{\beta_{2}}+\frac{(1-b) y_{h}}{\delta}-\frac{\Delta C}{\rho}=I, \\
& -\beta_{1} A_{0} y_{h}^{\beta_{1}-1}+\beta_{2} B_{1} y_{h}^{\beta_{2}-1}+\frac{(1-b)}{\delta}=0, \\
& -A_{0} y_{l}^{\beta_{1}}+B_{1} y_{l}^{\beta_{2}}+\frac{(1-b) y_{l}}{\delta}-\frac{\Delta C}{\rho}=-D, \\
& -\beta_{1} A_{0} y_{l}^{\beta_{1}-1}+\beta_{2} B_{1} y_{l}^{\beta_{2}-1}+\frac{(1-b)}{\delta}=0,
\end{aligned}
$$

where $\Delta C$ is the cost difference between nonirrigation systems and irrigation systems: $\Delta C=C_{1}-C_{0}$, and $b$ is the coefficient relating nonirrigated yield to irrigated yield, $y_{0}=b y_{1}$. The four simultaneous equations with four unknowns $\left(A_{0}, B_{1}, y_{h}\right.$, and $y_{l}$ ) are highly nonlinear in the thresholds $y_{h}$ and $y_{l}$, so that an analytical solution cannot be obtained. As a result, we use data to empirically parameterize the equations and then use MathCad 8 Professional (MathSoft, Inc.), a desktop application that combines math and visualization to meet the calculation, analysis, and reporting needs, to find a numerical solution for the simultaneous system.

\section{Data}

For the empirical analysis, we model a representative farm using Lubbock County data, a major cotton production county 
Table 1

Summary statistics of investment cost, pumping cost, exit cost, water use, and parameters used in real options calculation

\begin{tabular}{lc}
\hline Parameter & Value \\
\hline Irrigated farming & \\
Investment cost $(\$ / \mathrm{ha})$ & 740.7 \\
Exit cost $(\$ / \mathrm{ha})$ & 74.1 \\
Variable cost $(\$ / \mathrm{ha})$ & 771.8 (nonirrigated 655.0$)$ \\
Average yield $(\mathrm{kg} / \mathrm{ha})$ & 568.5 (nonirrigated 343.8) \\
Yield drift (trend) rate $(\alpha)$ & 0.054 \\
Yield volatility rate $(\sigma)$ & 0.267 \\
Risk-adjusted rate $(\rho)$ & 0.10 \\
Risk- and trend-adjusted rate $(\delta)$ & 0.046 \\
$\beta_{1}$ & 1.438 \\
$\beta_{2}$ & -1.959 \\
\hline
\end{tabular}

in the Texas High Plains that includes both nonirrigated and irrigated farmland with various irrigation systems. Table 1 reports the summary statistics of the data used in the analysis. The variable cost for nonirrigated cotton is estimated to be $\$ 1.89 / \mathrm{kg}$ (Texas Cooperative Extension, 2003a) and the yield per hectare averages $343.8 \mathrm{~kg}$. Thus, the estimated variable cost per hectare is $\$ 655.0$. For irrigated cotton, the budget data for sprinkler systems, not for LEPA, are officially reported. However, the energy cost of LEPA can be reduced by $13 \%$ in low-pressure sprinkler systems and by $40 \%$ in high sprinkler systems when a lift of 60.8 meter is conducted (Broner, 2005). In this study, we reduce the energy cost of LEPA by $27 \%$ compared to sprinkler irrigation systems. The variable cost for irrigated cotton is estimated to be $\$ 1.5 / \mathrm{kg}$ (Texas Cooperative Extension, 2003b) and the yield per hectare averages $568.5 \mathrm{~kg}$. Thus, the estimated variable cost per hectare is $\$ 771.8$. No study has been done for the clearing and restoring costs of irrigation systems. Thus, we assume that the exit cost is $10 \%$ ( $\$ 74.1 / \mathrm{ha})$ of the initial investment cost that is equivalent to the annual labor cost for irrigated cotton farming (Texas Cooperative Extension, 2003b). However, this assumption for the exit cost is relaxed in sensitivity analysis by allowing a $20 \%$ change.

An autoregressive process of order $1(\mathrm{AR}(1))$ model for the yield difference series with a constant term and a time trend was estimated to test the stability of the irrigated yield time series using the augmented Dickey-Fuller (ADF) unit root test. The ADF test statistic was -2.959 , whereas the $10 \%$ critical value for the unit root is -3.276 . Hence, we cannot reject the null hypothesis of a unit root, which supports using a geometric Brownian motion process. Regressing nonirrigated yield on

Table 2

Entry and exit thresholds for cotton-irrigated farming with low-energy precision application (LEPA) system in the Texas High Plains

\begin{tabular}{lll}
\hline Cotton price level $(\$ / \mathrm{kg})$ & Entry threshold $(\mathrm{kg} / \mathrm{ha})$ & Exit threshold $(\mathrm{kg} / \mathrm{ha})$ \\
\hline 0.70 & $1,019.2$ & 194.4 \\
1.15 & 627.2 & 119.6 \\
1.59 & 453.0 & 86.4 \\
\hline
\end{tabular}

irrigated yield series without an intercept gave a slope coefficient of $0.5955(P$-value $<0.001){ }^{2}$ Hence, we use $y_{0}=0.6 y_{1}$ for the proportional relationship between irrigated and nonirrigated yield. Irrigated cotton yields show a positive trend rate $(\alpha)$ of 0.054 and a volatility rate $(\sigma)$ of 0.267 . The positive and negative roots of the fundamental equation $\beta_{1}$ and $\beta_{2}$ are 1.438 and -1.959 , respectively. Finally, risk-adjusted discount rate is assumed to be $10 \%$, which is comparable to the rates used in other studies (Carey and Zilberman, 2002; Price and Wetzstein, 1999).

\section{Results}

Currently, the marketing loan rate sets the minimum price that a cotton farmer will receive. In addition, the farmer is eligible for the countercyclical payment and direct payment in the case that he/she has a base for cotton area. Among these federal government programs, the countercyclical payment and direct payment are decoupled from production and only the marketing loan rate is dependent on production. Thus, we set different price levels to evaluate their effects on the entry thresholds in terms of yield. These levels were $\$ 0.70 / \mathrm{kg}, \$ 1.15 / \mathrm{kg}$, and $\$ 1.59 / \mathrm{kg}$, respectively, based on the current marketing loan rate of $\$ 1.15 / \mathrm{kg}$ and a target price of $\$ 1.59 / \mathrm{kg}$ for countercyclical payment (USDA-FSA, 2005a,b). The lowest price of $\$ 0.70 / \mathrm{kg}$ is used to evaluate poor market conditions that may be caused by the elimination of the marketing loan program in the future.

\subsection{Entry and exit thresholds}

The results show that the entry thresholds of LEPA range from $453.0 \mathrm{~kg} / \mathrm{ha}$ at $\$ 1.59 / \mathrm{kg}$ to $1,019.2 \mathrm{~kg} / \mathrm{ha}$ at $\$ 0.70 / \mathrm{kg}$, depending on the price (Table 2). When compared to the county average yield, $568.5 \mathrm{~kg} / \mathrm{ha}$, it is clear that LEPA is profitable at the price level of $\$ 1.59 / \mathrm{kg}$. This is contrary to the earlier report by Seo et al. (2006) because they did not consider cost differences between irrigated farming and nonirrigated farming. The entry threshold, $627.2 \mathrm{~kg} / \mathrm{ha}$ at $\$ 1.15 / \mathrm{kg}$, is lower than the entry threshold of $636.7 \mathrm{~kg} / \mathrm{ha}$ recalculated from Seo et al. (2006) with the same conditions. Simultaneous decision making reduces the entry threshold for the LEPA system compared with single decision making, thus encouraging farmers to enter. This difference is caused by our model set up, which, unlike Seo et al. (2006), includes the value of the option to exit. This result is more correct because investors can exercise the option to exit irrigated farming if it is not profitable.

Even when the price is at the marketing loan rate, $\$ 1.15 / \mathrm{kg}$, the entry threshold is $627.2 \mathrm{~kg} / \mathrm{ha}$-higher than the county average yield. However, when price is at $\$ 0.70 / \mathrm{kg}$, the entry threshold is $1,019.2 \mathrm{~kg} / \mathrm{ha}$, much higher than the county average yield.

\footnotetext{
${ }^{2}$ Both yield series show first difference stability, while the yield series for nonirrigated yields shows weak nonstationary. Because the Durbin-Watson test of the linear combination of both yield series supports a stationary series (cointegrated), we simply run an OLS regression (i.e., a co-integrating regression).
} 
Table 3

Entry and exit thresholds and their sensitivities to changes in selected parameters in cotton-irrigated farming with low-energy precision application system in the Texas High Plains

\begin{tabular}{lclll}
\hline \multicolumn{2}{c}{ Parameter $^{\mathrm{a}}$} & & $\begin{array}{l}\text { Entry threshold } \\
(\mathrm{kg} / \mathrm{ha})^{\mathrm{b}}\end{array}$ & $\begin{array}{l}\text { Exit threshold } \\
(\mathrm{kg} / \mathrm{ha})^{\mathrm{b}}\end{array}$ \\
\hline Name & $\%$ Change & & 575.4 & 123.7 \\
Investment cost & $-20 \%$ & & 627.2 & 119.6 \\
& $0 \%$ & 678.3 & 116.4 \\
Variable cost difference & $-20 \%$ & 553.2 & 90.5 \\
& $0 \%$ & 627.2 & 119.6 \\
Exit cost & $20 \%$ & 700.4 & 149.9 \\
& $-20 \%$ & 626.7 & 121.9 \\
Risk-adjusted rate & $0 \%$ & 627.2 & 119.6 \\
& $20 \%$ & 627.7 & 117.4 \\
Drift (trend) rate & $-20 \%$ & 592.1 & 116.8 \\
& $0 \%$ & 627.2 & 119.6 \\
Volatility rate & $20 \%$ & 662.4 & 122.2 \\
& $-20 \%$ & 643.9 & 125.5 \\
& $0 \%$ & 627.2 & 119.6 \\
& $20 \%$ & 610.7 & 113.8 \\
& $-20 \%$ & 594.0 & 122.6 \\
& $0 \%$ & 627.2 & 119.6 \\
& $20 \%$ & 658.3 & 117.1 \\
\hline
\end{tabular}

${ }^{a}$ Base parameters used for the sensitivity analysis are $\$ 740.7 /$ ha in investment cost and $\$ 116.8 /$ ha in variable cost difference, respectively. Base parameter for risk-adjusted rate is $10 \%$, for drift rate $(\alpha)$ is 0.054 , and for volatility rate $(\sigma)$ is 0.267 , respectively.

${ }^{b}$ Entry thresholds are the levels of current yield flow to trigger irrigated farming that are evaluated at cotton price of $\$ 1.15 / \mathrm{kg}$.

Thus, the low prices may prevent or delay farmers from investing in irrigation systems.

The exit thresholds range from $86.4 \mathrm{~kg} / \mathrm{ha}$ to $194.4 \mathrm{~kg} / \mathrm{ha}$ depending on the price. These thresholds are much lower than the county average yield. Even in the worst scenario $(\$ 0.70 / \mathrm{kg})$, the exit threshold is $194.4 \mathrm{~kg} / \mathrm{ha}$ - far below the county average yield. This implies that once farmers enter irrigated farming, they likely would not leave irrigated farming until agricultural production and/or market conditions are very bad. In reality, the transitional probability from one irrigation system to another irrigation system was reported to be as low as 2\% in Texas (Feng and Segarra, 1992). This low level of transitional probability of irrigation systems may be partially explained by the high entry threshold and low exit threshold of irrigated farming. That is, sunk costs and uncertainty discourage farmers from exiting irrigated farming or replacing one irrigation system with another.

Table 3 shows the result of the sensitivity analysis at $\$ 1.15 / \mathrm{kg}$. Irrigated farming is not profitable even though the investment cost, exit cost, variable cost, risk-adjusted rate, and volatility rate decrease by $20 \%$, and the drift rate increases by $20 \%$. This implies that the investment decision is not sensitive to parameter changes. The exit thresholds also prove to be insensitive to any of the parameters considered. The exit thresholds remain low enough regardless of parameter changes.
A replacement decision requires that the yield increase or cost saving caused by a new irrigation system outweigh the investment cost required. However, water use in the Texas High Plains is costless, thus farmers produce the maximum yield level regardless of irrigation systems. The only advantage of the new irrigation system with high water application efficiency is the saving of an irrigation cost while requiring a large investment cost. In addition, the real options adds an opportunity cost caused by irreversibility and uncertainty to the replacement cost, thus increasing the entry threshold and decreasing the exit threshold further. A quick look at the cost structure between LEPA and traditional sprinkler systems reveals that the replacement decision is unlikely because the cost saving is only $\$ 29.0 /$ ha whereas the investment cost for LEPA is $\$ 740.7 /$ ha (note that a new investment has the effect of cost saving of $\$ 135.5 /$ ha at county average yield and marketing loan rate price, which is 4.76 times higher than $\$ 29.0 /$ ha in a replacement investment). This elucidates how unprofitable it is to replace an old irrigation system with a new system with better water application efficiency even under the more pro-investment parameter constellation outlined above, which supports the low transitional probability from the previous study by Feng and Segarra (1992). This also supports King and Kincaid's (2005) result that the increased cost of LEPA relative to a low-pressure sprinkler system is not justified by the marginal increase in application efficiency.

\subsection{Implication for water saving}

Irrigated areas in Lubbock and Texas as a whole peaked at 107 thousand ha and 1,223 thousand ha in 1980, respectively (Fig. 1). Since then these areas have been reduced to, respectively, 80 thousand ha and 976 thousand ha in 2002 with some fluctuations according to production and/or market condition (USDA-NASS, 2005). These area series move closely together with a correlation coefficient of 0.94 . Irrigated area has slightly increased since the LEPA system was disseminated in 1992 compared with the period of 1982-1990. The area increase has mainly been caused by market conditions that also contribute to the profitability of new irrigation systems. Thus, it is not easy to differentiate the effect that irrigation systems have on area increases from the effect of market conditions. However, we know that new irrigation systems increase yield compared to nonirrigation systems, so that may contribute to area increases to some degree.

At the state level, groundwater use was reported separately from surface water use from 1980 to 1997, skipping 19811983 (Texas Water Development Board, 2005). As shown in Fig. 1, groundwater use has also been fluctuating according to irrigated area. The correlation between irrigated area and water use is 0.88 in Lubbock County and 0.85 in Texas as a whole. These high correlations show high responsiveness of water use to irrigated area. Thus, as better irrigation systems encourage more cotton production, the water usage increases. Per-hectare 


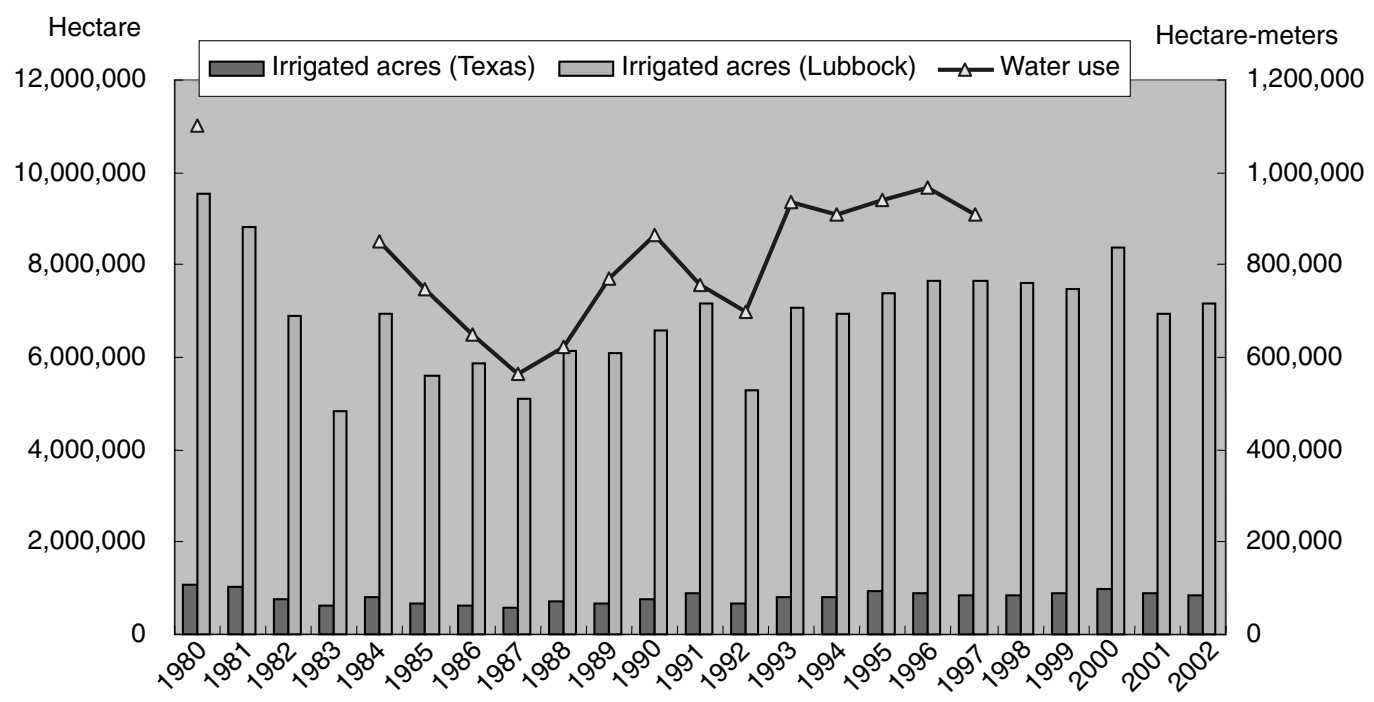

Fig. 1. Cotton-irrigated area in Lubbock and Texas and groundwater usage in Texas.

water use obtained by dividing water use by irrigated area has slightly dropped showing a positive trend since 1992, the year LEPA began to be disseminated (Fig. 2). However, overall water use has increased despite the decrease in per-hectare water use. These facts may support Feng and Segarra (1992) who argue that the profitability of new irrigation systems increases water use by increasing irrigated area.

However, it is noticeable that although a small portion of the irrigated area continues to fluctuate, the majority of cotton area does not. This majority is still affected by the low exit threshold and low transitional probability. That is, the change in water use is only affected by marginal cotton areas that fluctuate with market conditions, not by major cotton areas that are not easily affected by market conditions. Thus, given the low exit threshold, nonsensitivity of the exit threshold to parameter change, and low transitional probability from one irrigation system to another makes us doubt that communities will have much success at getting farmers to conserve water. In addition, a small decrease in per-hectare water use with a

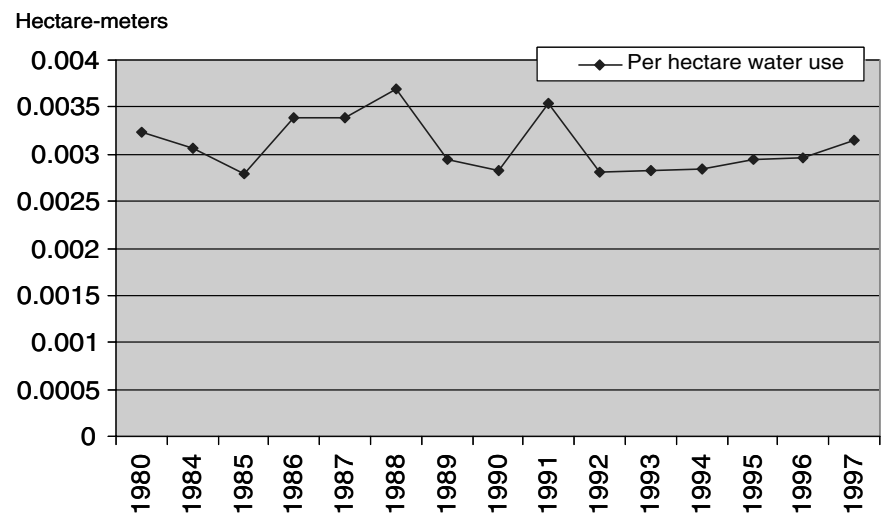

Fig. 2. Per-hectare groundwater use in Texas. positive trend since 2002 shows that the expectation of water saving from new irrigation systems is not very successful either.

To attain the goal of water saving in Lubbock County, the target of new irrigation systems must be current farmers with traditional irrigation systems rather than marginal farmers (or new farmers). That is, Lubbock County needs to focus on supporting the replacement decision from old irrigation systems to new irrigation systems with high water application efficiency. This would eventually reduce per-hectare water use and overall water use to the amount Lubbock County desires. However, a small gain in irrigation cost but a large investment cost as well as sunk costs caused by irreversibility and uncertainty may prevent the replacement decision. Thus, it is likely that Lubbock County will have to subsidize the replacement of traditional irrigation systems with new irrigation systems and relax financial restrictions, such as with a policy subsiding interest rates so that farmers using older irrigation systems face a low interest rate to obtain new irrigation systems.

It should be noted that an irrigation equipment replacement subsidy would in some sense be a second-best policy to partially or completely offset effects due to current U.S. federal price support policy. Current U.S. domestic assistance to cotton farmers $(\$ 0.44 / \mathrm{kg})$ is relatively high compared with other cotton-producing countries (Pan et al., 2005) and increases the area of irrigated cotton production (and hence water use) in the Texas High Plains beyond what would occur under free trade. In addition, any irrigation equipment replacement subsidy should be limited to farmers currently producing irrigated cotton to help reduce area expansion effects due to a replacement subsidy. These extra-marginal (area expansion) effects (as well as intra-marginal/input use effects) have been studied for many federal programs, especially for crop insurance (e.g., Goodwin and Smith, 2003; Hennessy, 1998; Seo et al., 2005; Wu, 1999). Hence, any policy to encourage adoption of more water-efficient irrigation technology should be carefully 
studied before implementation to quantify the magnitude of such effects so as to obtain a more comprehensive estimate of policy impacts on regional water use.

\section{Conclusion}

Water shortage has been a significant issue for several decades in the Texas High Plains. Agriculture has been identified as the main activity contributing to this shortage. To address this issue, many efforts have been made to introduce or develop sophisticated irrigation systems with high levels of water application efficiency. The alternatives considered include the LEPA system, the SDI system, and the VRI system. Among these irrigation systems, we only consider the LEPA system because it has been demonstrated to be the most profitable (Seo et al., 2006). In this study we analyze both the entry and exit decisions for the LEPA system simultaneously, so that more accurate decision making is obtained compared with considering the entry decision alone. In addition, we derive the implications in terms of water conservation in Lubbock County from the exit decision. Specifically, a real options approach is used to evaluate the economic feasibility of LEPA. For this analysis, a representative cotton farm is set up using data from Lubbock County, a major cotton production area in the Texas High Plains, which currently includes both nonirrigated and irrigated farmland with various irrigation systems.

Our results show that considering the simultaneous decision making for the entry and exit of irrigation systems reduces the entry threshold for the LEPA system compared with only considering single decision making, thus encouraging farmers' entry decision. The LEPA system is shown to be profitable only with market prices over $\$ 1.59 / \mathrm{kg}$. The exit threshold is very low even with a price level as low as $\$ 0.70 / \mathrm{kg}$. Sensitivity analysis also shows that the exit threshold is not sensitive to parameter changes. This implies that once farmers begin irrigated farming, they will not stop irrigated farming unless the market or production conditions are very bad. This low exit threshold caused by irreversibility and uncertainty in irrigated farming may partially explain the observed low transitional probability from one irrigation system to another (Feng and Segarra, 1992).

Since the LEPA system began to be disseminated in 1992, cotton area has increased slightly with some fluctuations. Groundwater use has also increased with a high correlation to area increases. Per-hectare water use slightly decreased following a positive trend after the introduction of the LEPA in 1992. The increment of cotton area and water use fluctuation are caused by marginal farmers who easily and repeatedly leave and enter irrigated farming according to the market conditions. However, the majority of cotton farmers do not change their irrigated area levels. This can be explained by the low exit threshold and low transitional probability. Thus, given the low exit threshold, nonsensitivity of the exit threshold to parameter changes, low transitional probability, and the slight decrease in per-hectare groundwater use with a positive trend, the efforts made to save water have not been successful.

Thus, to attain the goal of water saving, Lubbock County needs to focus on current farmers with old irrigation systems, who make up the majority of the potential market for new irrigation systems, rather than marginal farmers, who are the minority. That is, Lubbock County needs to help support the replacement decision from old to newer and more applicationefficient irrigation systems. Of course, this support must exclude marginal farmers who would contribute to expanding the cotton-producing area and thus increase water use. Such a policy would eventually lead to a reduction in per-hectare water use and overall water use in Lubbock County. For this purpose, Lubbock County needs to subsidize the replacement of traditional irrigation systems with new irrigation systems, for example, by relaxing the financial restrictions for current irrigated farmers to obtain new irrigation systems. However, it should be noted that the subsidy likely distorts farmers' production decisions, even if the replacement decision remains confined to those currently using irrigation. The possibility of production distortions from the replacement subsidy needs to be carefully evaluated before such a policy is implemented.

The issues evaluated in this study and the manner in which they were evaluated may have broad implications in other locations. Specifically, many areas currently experiencing and expected to experience significant water availability constraints in the future need to internalize into their policy making that farmers are likely to operate under irrigated conditions much longer than it would seem rational because of the option value.

\section{References}

Abel, A. B., Dixit, A. K., Eberly, J. C., Pindyck, R. S., 1996. Options, the value of capital, and investment. Q. J. Econ. 111, 753-777.

Almas, L. K., Amossono, S. H., Marek, T., Colette, W. A., 2003. Economic feasibility of precision irrigation in the Northern Texas High Plains. Paper presented at the Southern Agricultural Economics Association Annual Meeting, Mobile, AL, 1-5 February.

Amosson, S., New, L., Almas, L., Brets, F., Marek, T., 2001. Economics of Irrigation Systems. Bulletin B-6113, Texas A\&M University, Texas Cooperative Extension Service, College Station, TX.

Arabiyat, T. S., Segarra, E., Willis, D. B., 1999. Sophisticated irrigation technology and biotechnology adoption: impact on ground water conservation. AgBioForum 2, 132-136.

Broner, I., 2005. Irrigation: center-pivot irrigation systems. Available at http://www.ext.colostate.edu/Pubs/crops/04704.pdf (accessed July 2006).

Carey, J. M., Zilberman, D., 2002. A model of investment under uncertainty: modern irrigation technology and emerging markets in water. Am. J. Agric. Econ. 84, 171-183.

Dixit, A. K., Pindyck, R. S., 1994. Investment under Uncertainty. Princeton University Press, Princeton, NJ.

Feng, Y., Segarra, E., 1992. Forecasting the use of irrigation systems with transition probability in Texas. Tex. J. Agric. Res. 5, 59-66.

Goodwin, B. K., Smith, V. H., 2003. An ex-post evaluation of the Conservation Reserve, Federal Crop Insurance, and other government programs: program participation and soil erosion. J. Agric. Res. Econ. 28, 201-216. 
Hennessy, D. A., 1998. The production effects of agricultural income support policies under uncertainty. Am. J. Agric. Econ. 80, 46-57.

Isik, M., Coble, K. H., Hudson, D. H., House, L. O., 2003. A model of entry-exit decisions and capacity choice under demand uncertainty. Agric. Econ. 28, 215-224.

Johnson, S. H., Vermillion, D. L., Sagardoy, J. A. (Eds.), 1995. Irrigation management transfer: selected papers from the International Conference on Irrigation Management Transfer. 20-24 September 1994 Wuhan, China. Water Report 5. FAO/International Water Management Institute, Rome.

King, B. A., Kincaid, D. C., 2005. Optimal performance from center pivot sprinkler systems. Cooperative Extension System-Agricultural Experiment Station. BUL 797. University of Idaho. Available at http:// info.ag.uidaho.edu/resources/PDFs/BUL0797.pdf (accessed July 2006).

Meinzen-Dick, R., Raju, K. V., Gulati, A., 2002. What affect organization and collective action for managing resources? Evidence from canal irrigation systems in India. World Dev. 30, 649-666.

Merton, R. C., 1973. Theory of rational option pricing. Bell J. Econ. Manage. Sci. 4, 143-183.

Molden, D., Sakthivadivel, R., Samad, M., 2001. Accounting for change in water use and the need for institutional adaptation. In: Abernethy, C. L. (Ed.), Intersectoral Management of River Basins: Proceedings of an International Workshop on Integrated Water Management in Water-Stress River Basins in Developing Countries: Strategies for Poverty Alleviation and Agricultural Growth, Loskop Dam, South Africa, 16-21 October 2000. IWMI; DSE, Colombo, Sri Lanka, pp. 73-87.

National Research Council, 1996. A New Era for Irrigation. National Academic Press, Washington, DC.

Pan, S., Fadiga, M., Mohanty, S., Welch, M., Ethridge, D., 2005. Cotton in a free trade world. Briefing Paper CERI-BP05-02, Cotton Economics Research Institute, Texas Tech University. Available at http://www.aaec.ttu. edu/ceri/policy/publications/publications/Cotton $\% 20$ in $\% 20 \mathrm{a} \% 20$ Free $\% 20$ Trade\%20World\%20(briefing\%20paper).pdf (accessed July 2006).

Pindyck, R. S., 1991. Irreversibility, uncertainty, and investment. J. Econ. Lit. 29, 1110-1148.

Price, T. J., Wetzstein, M. E., 1999. Irreversible investment decisions in perennial crops with yield and price uncertainty. J. Agric. Res. Econ. 24, 173-185.

Purvis, A., Boggess, W. G., Moss, C. B., Holt, J., 1995. Technology adoption decisions under irreversibility and uncertainty: an ex ante approach. Am. J. Agric. Econ. 77, 541-551.
Segarra, E., Feng, Y., 1994. Irrigation technology adoption in the Texas High Plains. Tex. J. Agric. Nat. Res. 7, 71-83.

Seo, S., Mitchell, P. D., Leatham, D. J., 2005. Effects of Federal Risk Management Programs on optimal acreage allocation and nitrogen use in a Texas Cotton-Sorghum System. J. Agric. Appl. Econ. 37, 685699.

Seo, S., Segarra, E., Mitchell, P. D., Leatham, D. J., 2006. Irrigation technology adoption in the Texas High Plains: a real options approach. Unpublished Paper. Texas Tech University.

Shah, T., 2005. Sustainable Groundwater Management. Annual Report 2004/2005. International Water Management Institute. Available at http://www.iwmi.cgiar.org/pubs/Areps/2004_2005/c34.htm (accessed July 2006)

Texas Cooperative Extension, 2003a. Estimated costs and returns per acre cotton, $2 \times 1$, dryland (skip-row) 2004 projected costs and returns per ground acre. Available at http://agecoext.tamu.edu/budgets/district/ 1and2/2004/c2x1dsr.pdf (accessed July 2006).

Texas Cooperative Extension, 2003b. Estimated costs and returns per acre cotton, sprinkler irrigated (roundup-ready seed) 2004 projected costs and returns per acre. Available at http://agecoext.tamu.edu/budgets/district/ 1and2/2004/csirrs.pdf (accessed July 2006).

Texas Water Development Board, 2005. Historical Ground and Surface Water Use in Texas: 1980-1997. Available at http://www.twdb.state.tx.us/data/ popwaterdemand/2003Projections/HistoricalWaterUse/TexasHistorical WaterUse.htm (accessed July 2006).

Trigeorgis, C. G., 1996. Real Options: Managerial Flexibility and Strategy in Resource Allocation. MIT Press, Cambridge, MA.

United States Department of Agriculture, Farm Service Agency, 2005a. 2005 Crop Years National Averages. Available at http://www.fsa.usda.gov/ dafp/psd/2005CropYearsNationAverages.pdf (accessed July 2006).

United States Department of Agriculture, Farm Service Agency, 2005b, Fact Sheet. Available at http://www.fsa.usda.gov/pas/publications/facts/ html/dcp03.htm (accessed July 2006).

United States Department of Agriculture, National Agricultural Statistics Service, 2005. Quick Stats: Agricultural Statistics Data Base. Available at http://www.nass.usda.gov/QuickStats (accessed July 2006).

Wu, J., 1999. Crop insurance, acreage decisions, and nonpoint-source pollution. Am. J. Agric. Econ. 81, 305-320. 